\title{
ANALISIS TSE FACTOR TERHADAP SIGNAL TO NOISE RATIO DAN CONTRAST TO NOISE RATIO PADA PEMBOBOTAN T2 TURBO SPIN ECHO POTONGAN AXIAL MRI BRAIN
}

\section{ANALYSIS OF TSE FACTOR TO SIGNAL TO NOISE RATIO AND CONTRAST TO NOISE RATIO AT T2 WEIGHTED TURBO SPIN ECHO AXIAL SLICE OF BRAIN MRI}

\author{
Novelsa Chintya Prabawati ${ }^{1)}$, Siti Masrochah ${ }^{2)}$, Sri Mulyati ${ }^{3)}$ \\ ${ }^{1,2,3)}$ Health Polytechnics of Semarang-Indonesia \\ e-mail: novelsacp@gmail.com
}

\begin{abstract}
Background: TSE factor is parameters that affect Signal to Noise Ratio (SNR) and Contrast to Noise Ratio (CNR). TSE factor for brain MRI examination is a long TSE factor. There are differences when using TSE factor. At the theory, the brain MRI examination is using TSE factor $\geq 16$ while at Siloam Surabaya Hospital was using TSE factor 14. The writer ever seen some noises at brain MRI image therefore the radiographer doing modification of TSE factor. The purpose of this research are to determine the influence of modification in the TSE factor value against SNR and CNR and to define the SNR and CNR optimum from that.

Methods: This research is a quantitative study with an experimental approach. This research was done by MRI Philips Achieva 1,5 T with 10 modification TSE factor $(8,10,12,14,16,18,20,22,24$ and 26). SNR and CNR obtained by measurement of ROI in the grey matter, white matter and CSF with the result an average signal and compared with the average standard deviation of the background image. Data was analyzed by linear regression test to know the influence of TSE factor against SNR and CNR and data was analyzed by descriptive test mean rank to obtain the optimum TSE factor value.

Result: The result showed that there was the inluence of TSE factor to SNR and CNR at T2W TSE axial brain. There was a significant correlation between TSE factor with all of area SNR and CNR with coefficient correlation of SNR grey matter $\mathrm{r}=0,591$, with coefficient correlation of SNR white matter $r=0,604$, with coefficient correlation of SNR CSF $r=0,687$, with coefficient correlation of CNR CSF-grey matter $\mathrm{r}=0,690$, with coefficient correlation of CNR CSF-white matter $\mathrm{r}=0,658$. The significant value of linear regression test is $(0,000 *)<p$ value $(0,05)$. TSE factor optimum value at T2W TSE axial brain was TSE factor value 10 for SNR with mean rank SNR 45,05 and TSE factor value 8 for CNR with mean rank CNR 35,43.

Conclusion: There was the influence of TSE factor to SNR and CNR at T2W TSE axial brain. TSE factor optimum value in brain MRI T2W TSE axial is 10 to SNR and TSE factor 8 to CNR.
\end{abstract}

Keywords: TSE factor, SNR, CNR, Brain, axial

\section{PENDAHULUAN}

Dewasa ini perkembangan ilmu dan teknologi kedokteran mengalami kemajuan yang sangat pesat dan modern, khususnya pelayanan medis radiologi. Pada bidang radiodiagnostik, digunakan modalitas Magnetic Resonance Imaging (MRI) dalam membantu menegakkan diagnosis terutama dalam memberikan informasi yang lebih nyata tentang hubungan anatomi dan kelainan-kelainan patologis dari obyek yang diperiksa. MRI merupakan scanning non ionizing yang mampu mencitrakan organ yang diperiksa. MRI menjadi modalitas pencitraan yang utama untuk mengevaluasi jaringan lunak terutama otak, tulang belakang dan susunan saraf pusat. (Simanjuntak, dkk. 2014).

Jenis pemeriksaan MRI yang berfungsi mengevaluasi jaringan lunak terutama pada otak adalah pemeriksaan MRI brain. MRI brain juga digunakan untuk mengevaluasi susunan saraf pusat, memperlihatkan fossa posterior, karakterisasi jaringan dengan menggunakan spectroscopy dan pemeriksaan vaskuler yang dapat dilakukan tanpa menggunakan media kontras. Protokol yang digunakan pada pemeriksaan MRI brain adalah T1 potongan sagital pada sekuen Spin Echo (SE) atau Turbo Spin Echo (TSE) atau Fast Field Echo (FFE), T2 potongan axial SE atau TSE Proton Density (PD), T2 potongan coronal SE atau TSE PD dengan sekuen tambahan T2 potongan axial Single Shot TSE (SS-TSE), potongan axial Fluid Attenuation Inversion Recovery (FLAIR) atau Echo Planar Imaging (EPI), potongan axial Diffusion Weigthted Imaging (DWI) dan 3 dimensi (3D) (Westbrook, 2014).

Parameter MRI yang digunakan untuk meminimalisir waktu pada pemeriksaan salah satunya dengan digunakannya Turbo Spin Echo (TSE) factor atau Turbo factor atau Echo Train Length (ETL) pada sekuen Turbo Spin Echo (TSE) atau Fast Spin Echo (FSE). TSE merupakan sekuen yang sama dengan SE akan tetapi memiliki waktu scanning lebih singkat. Pada TSE terdapat TSE factor yang menyebabkan satu Time Repetition (TR) dapat mengisi lebih dari satu echo di dalam $k$ space. Pemberian sekuen pulsa TSE yang digunakan adalah satu kali pulsa $90^{\circ}$ diikuti dengan multiple $180^{\circ}$ dalam satu TR. Pengaplikasian beberapa pulsa $180^{\circ}$ dalam tiap TR akan menghasilkan rangkaian echo yang disebut TSE factor. (Simanjuntak, dkk. 2014).

Menurut Elster (2015) TSE factor berdampak dengan kualitas citra, TSE factor yang lebih panjang dihasilkan pada 
pembobotan T2 karena pembobotan T2 memiliki TE (Time Echo) yang panjang untuk menghasilkan sinyal. Menurut Anonim (2013) pada MRI Philips, rentang TSE factor yang panjang adalah $10-25$. Menurut Westbrook (2011) TE yang panjang adalah $\geq 70 \mathrm{~ms}$. TSE factor yang lebih panjang mengakibatkan penurunan Signal to Noise Ratio (SNR) karena echo-echo selanjutnya akan lemah dan berpengaruh terhadap Contrast to Noise Ratio (CNR). Menurut Simanjuntak, dkk. (2014) TSE factor pada pembobotan T2 TSE dapat menyebabkan blurring yang menurunkan kualitas citra SNR dan kontras citra atau CNR. Menurut Westbrook (2014) TSE factor yang digunakan adalah TSE factor panjang, yaitu: $\geq 16$.

Kualitas citra dipengaruhi oleh beberapa faktor, yaitu: SNR, CNR, spatial resolution dan scan time. Pada gambaran MRI brain diperlukan kejelasan kontras antar organ dan diperlukan noise yang minimal, maka dari itu diperlukan SNR dan CNR yang baik. SNR merupakan perbandingan antara besarnya amplitudo sinyal dengan amplitudo noise. Faktorfaktor yang mempengaruhi SNR antara lain sekuen pulsa SE dan TSE (dengan TSE factor), TR, TE, flip angle, coil yang digunakan, matrix, field of view (FOV), slice thickness, bandwidth dan Number of Signal Averages (NSA). CNR diperoleh dari SNR. CNR adalah perbedaan SNR antara organ yang saling berdekatan. Selain dipengaruhi oleh SNR, CNR dapat dipengaruhi oleh contrast agents, sekuen T2, penggunaan Short Tau Inversion Recovery (STIR) dan FLAIR dan penyangatan aliran dengan penggunaan Time of Flight (TOF) (Westbrook, 2014).

Menurut Muzio (2017) sekuen T2 TSE pada MRI brain digunakan untuk mengevaluasi basal cistern, sistem ventrikuler dan subdural space. Sekuen T2 TSE menciptakan sinyal yang kuat seperti pada aliran pembuluh darah dan cairan cerebro spinalis atau Cerebrospinal Fluid (CSF). Sekuen T2 TSE dapat memperlihatkan keadaan patologis. Patologis ditandai dengan peningkatan vaskularisasi sehingga memiliki kandungaan air yang lebih tinggi dan patologis pada otak akan tampak hiperintens. Menurut Cooper (2012) pemeriksaan pada MRI brain akan terlihat jelas pada potongan axial karena dapat memperlihatkan organ atau jaringan pada otak. T2 MRI brain axial dapat memperlihatkan ukuran dan simetris dari ventrikel.

Sekuen yang digunakan pada pemeriksaan MRI brain rutin di Rumah Sakit Siloam Surabaya adalah axial DWI, axial FLAIR, Magnetic Resonance Angiography (MRA), axial, sagital dan coronal pembobotan T2 TSE, T1 SE dan T2 FFE. TSE pada pembobotan T2 dilakukan dengan potongan axial, sagital dan coronal brain. Berdasarkan pengamatan penulis, penggunaan pembobotan T2 TSE pada pemeriksaan MRI brain di Instalasi Radiologi Rumah Sakit Siloam Surabaya adalah untuk mempersingkat waktu pemeriksaan.

Selama penulis melakukan praktik di Rumah Sakit Siloam Surabaya, TSE factor yang sering digunakan pada pemeriksaan MRI brain adalah 14 yang merupakan protokol rutin pemeriksaan MRI brain dari pesawat MRI Philips Achieva 1,5 T. Hal tersebut sesuai dengan teori bahwa TSE factor yang digunakan pada pemeriksaan MRI brain adalah TSE factor pada rentang TSE factor panjang. Menurut
Westbrook (2014) TSE factor yang digunakan pada pemeriksaan MRI brain yaitu TSE factor yang panjang atau $\geq$ 16. Penulis pernah menjumpai adanya noise (titik- titik putih pada area background) pada pemeriksaan MRI brain, maka radiografer melakukan modifikasi nilai TSE factor. Dilakukan pengulangan scanning pembobotan T2 TSE dengan mengurangi nilai TSE factor, sehingga dapat mengurangi adanya noise akan tetapi scan time menjadi lebih lama.

\section{METODE}

Jenis penelitian ini adalah penelitian kuantitatif dengan pendekatan eksperimental. Pemgambilan data dilakukan pada bulan April 2017 di Instalasi Radiologi Rumah Sakit Siloam Surabaya. Populasi dan sampel penelitian adalah citra MRI T2 TSE potongan axial brain dengan menggunakan 10 nilai TSE factor dari 8 probandus. Prosedur penelitian dengan melakukan scanning MRI brain pepmbobotan T2 TSE potongan axial, dengan mengatur parameter TSE factor yang terdapat pada alat dengan nilai TSE factor 8, 10, 12, 14, 16, $18,20,22,24$ dan 26 dan parameter lain tetap. Kemudian dilakukan penilaian hasil citra pada brain dengan mengukur nilai SNR dan CNR pada area yang akan dievaluasi dan area background untuk mengetahui rata-rata sinyal masing-masing citra. Pengukuran SNR dilakukan dengan cara membuat ROI dengan area ROI $0,1 \mathrm{~cm}^{2}$ pada area grey matter, white matter dan CSF. Pengukuran CNR dilakukan dengan cara menghitung selisih nilai SNR dua jaringan. CNR dalam penelitian ini adalah selisih SNR antara CSF dengan grey matter dan CSF dengan white matter.

Analisis data dilakukan uji statistik dengan aplikasi SPSS v. 17.0. data tersebut diuji dengan Shapiro-Wilk test untuk mengetahui normalitas data. Selanjutnya data diolah dengan uji regresi linier untuk mengetahui ada atau tidaknya pengaruh nilai SNR dan CNR dengan TSE factor terhadap citra MRI brain potongan axial. Serta dilakukan uji descriptive mean rank untuk mengetahui nilai TSE factor yang optimal.

\section{HASIL}

Penelitian ini dilakukan terhadap 8 probandus berjenis kelamin laki-laki dan perempuan dengan rentang usia 19 tahun sampai 26 tahun yang dilakukan pemeriksan MRI brain dengan pembobotan T2 TSE potongan axial menggunakan 10 nilai TSE factor, yaitu 8, 10, 12, 14, 16, 18, 20, 22, 24 dan 26.

Tabel 1. Karakteristik probandus pemeriksaan MRI brain potongan axial

\begin{tabular}{clcc}
\hline Probandus & Nama & Jenis Kelamin & Umur \\
\hline 1 & Nn. A & Perempuan & 21 tahun \\
2 & Sdr. H & Laki - laki & 19 tahun \\
3 & Sdr. D & Laki - laki & 19 tahun \\
4 & Sdr. RDP & Laki - laki & 26 tahun \\
5 & Sdr. J & Laki - laki & 20 tahun \\
6 & Sdr. RA & Laki - laki & 20 tahun \\
7 & Nn. R & Perempuan & 22 tahun \\
8 & Nn. S & Perempuan & 21 tahun \\
\hline
\end{tabular}


Dari kedelapan probandus tersebut diperoleh nilai SNR dan CNR dari nilai TSE factor pada pemeriksaan MRI brain dengan pembobotan T2 TSE potongan axial.
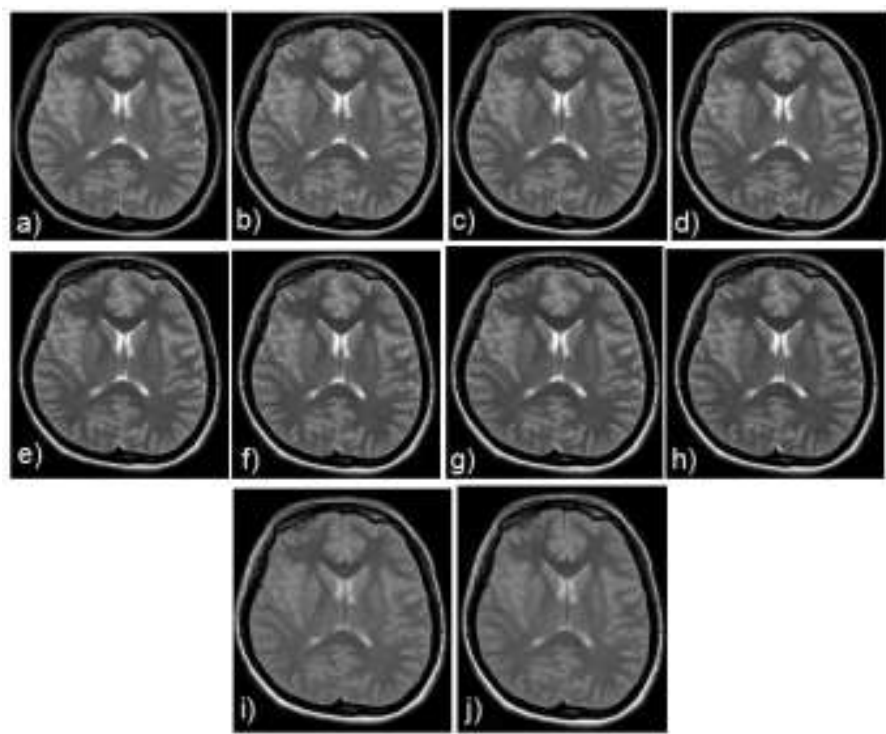

Gambar 1. Citra probandus 1 dengan a)TSE factor 8 b)TSE factor 10 c)TSE factor 12 d)TSE factor 14 e)TSE factor 16 f)TSE factor 18 g)TSE factor $20 \mathrm{~h}$ )TSE factor $22 \mathrm{i}$ )TSE factor $24 \mathrm{j}$ )TSE factor 26

Pengaruh TSE factor terhadap SNR dan CNR pada pembobotan T2 TSE potongan axial MRI brain

Penilaian citra dilakukan dengan membuat ROI dan mengukur SNR dari masing-masing citra yaitu SNR grey matter, white matter dan CSF. Setelah perhitungan SNR diteruskan dengan perhitungan CNR yang merupakan selisih SNR yang berdekatan dalam satu citra, area tersebut adalah CNR CSF-white matter dan CNR CSF-grey matter.

Data SNR dan CNR yang diperoleh dilakukan uji normalitas menggunakan Shapiro-Wilk test untuk mengetahui data berdistribusi normal atau tidak. Berdasarkan hasil uji normalitas data, maka didapatkan data berdistribusi normal dengan nilai signifikansi $\rho$ value $>0,5$.

\section{Hasil uji statistik pengaruh TSE factor terhadap SNR}

Untuk mengetahui pengaruh yang bermakna dan signifikan antara berbagai nilai TSE factor terhadap SNR pada MRI brain T2W TSE, maka perlu dilakukan uji regresi linier dengan taraf keberartian. Uji regresi dilakukan pada setiap area pada brain yaitu grey matter, white matter dan CSF.

Tabel 2. Hasil uji regresi TSE factor terhadap SNR setiap area pada

\begin{tabular}{|c|c|c|c|}
\hline \multicolumn{4}{|c|}{ brain } \\
\hline SNR & $\mathbf{r}$ & R Square & $\rho$ value \\
\hline Grey matter & 0,591 & 0,349 & \\
\hline White matter & 0,604 & 0,356 & $<0,05$ \\
\hline CSF & 0,687 & 0,472 & \\
\hline
\end{tabular}

Untuk melihat hubungan nilai TSE factor dengan SNR brain setiap area dapat dilihat pada gambar 2, gambar 3, gambar 4.

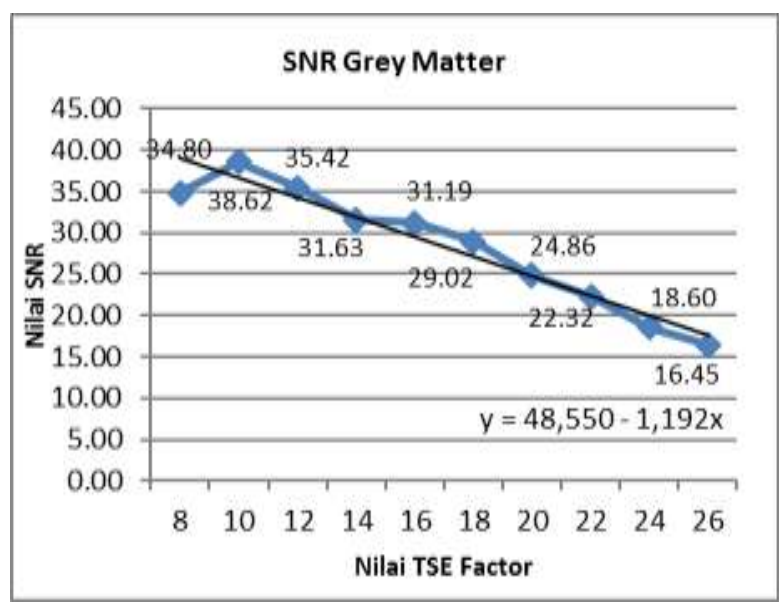

Gambar 2. Grafik pengaruh TSE factor terhadap SNR pada area grey matter

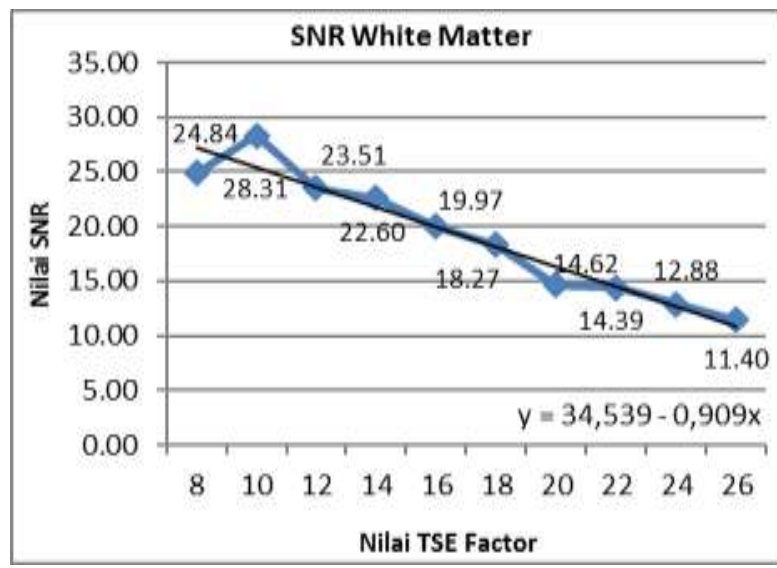

Gambar 3. Grafik pengaruh TSE factor terhadap SNR pada area white matter

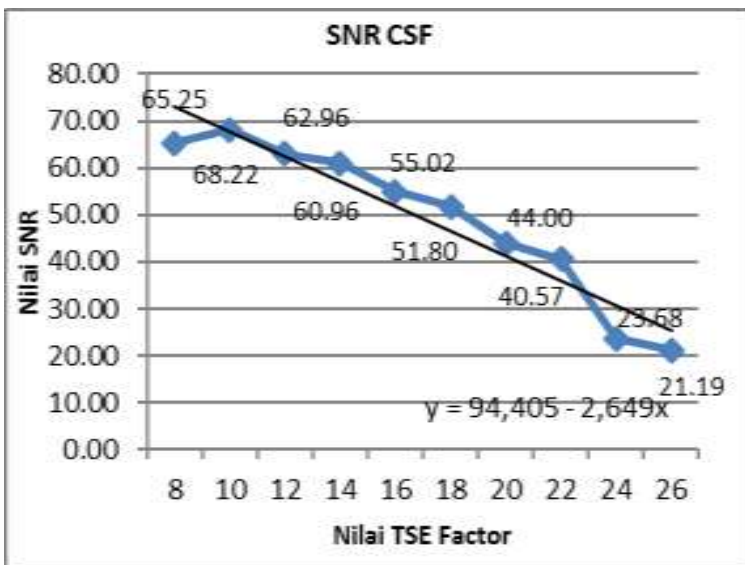

Gambar 4. Grafik pengaruh TSE factor terhadap SNR pada area CSF

\section{Hasil uji statistik pengaruh TSE factor terhadap CNR}

Untuk mengetahui pengaruh yang bermakna dan signifikan antara berbagai nilai TSE factor terhadap nilai CNR pada MRI brain T2W TSE, maka perlu dilakukan uji regresi linier dengan taraf keberartian antara TSE factor dengan CNR pada area CSF-white matter dan CNR CSF-grey matter. 
Tabel 3. Hasil uji regresi TSE factor terhadp CNR setiap area pada brain

\begin{tabular}{cccc}
\hline CNR & $\mathbf{r}$ & $\boldsymbol{R}$ Square & $\boldsymbol{\rho}$ value \\
\hline CSF - grey matter & 0,690 & 0,477 & \\
CSF - white matter & 0,658 & 0,433 & $<0,05$ \\
\hline
\end{tabular}

Untuk melihat hubungan nilai TSE factor dengan SNR brain setiap area dapat dilihat dengan grafik:

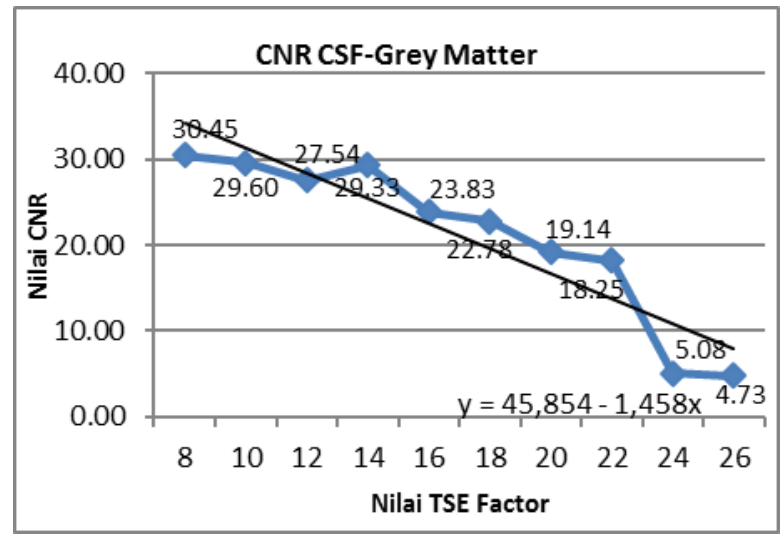

Gambar 5. Grafik pengaruh TSE factor terhadap CNR pada area CSF-grey matter

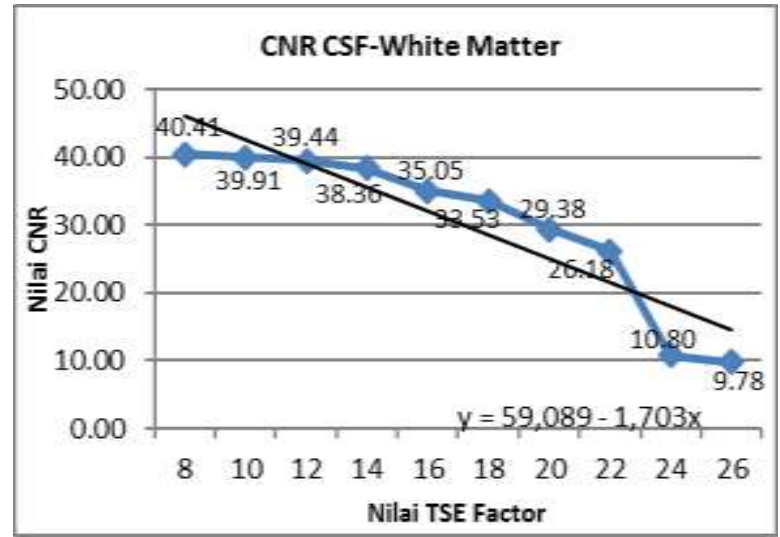

Gambar 6. Grafik pengaruh TSE factor terhadap CNR pada area CSF-white matter

Nilai TSE factor yang paling optimal untuk menghasilkan SNR dan CNR pada pemeriksaan MRI brain dengan pembobotan T2 TSE

Untuk mengetahui nilai TSE factor yang paling optimal maka dilakukan uji descriptive mean rank. Berdasarkan uji mean rank maka didapatkan nilai seperti tabel 4.

Berdasarkan grafik gambar 7 menunjukkan bahwa pada grafik mean rank SNR dan CNR keduanya mengalami kecenderungan turun yaitu semakin tinggi nilai TSE factor maka nilai SNR dan CNR semakin menurun. Menurut Westbrook (2014) nilai TSE factor yang digunakan pada pemeriksaan MRI brain adalah TSE factor yang panjang dengan nilai $\geq 16$. Dari hasil penelitian tersebut nilai TSE factor 16 berada pada urutan ke 5 mean rank SNR dan CNR brain. Diperoleh mean rank SNR pada TSE factor 16 adalah 35,39 dan pada CNR adalah 29,44.
Tabel 4. Mean rank SNR

\begin{tabular}{ccc}
\hline No. & TSE Factor & Nilai Mean Rank \\
\hline 1 & 8 & 41,63 \\
2 & 10 & 45,05 \\
3 & 12 & 40,63 \\
4 & 14 & 38,40 \\
5 & 16 & 35,39 \\
6 & 18 & 33,03 \\
7 & 20 & 27,83 \\
8 & 22 & 25,76 \\
9 & 24 & 18,39 \\
10 & 26 & 16,37 \\
\hline
\end{tabular}

Tabel 5. Mean rank CNR

\begin{tabular}{ccc}
\hline No. & TSE Factor & Nilai Mean Rank \\
\hline 1 & 8 & 35,43 \\
2 & 10 & 34,75 \\
3 & 12 & 33,49 \\
4 & 14 & 33,84 \\
5 & 16 & 29,44 \\
6 & 18 & 28,16 \\
7 & 20 & 24,26 \\
8 & 22 & 22,22 \\
9 & 24 & 7,94 \\
10 & 26 & 7,26 \\
\hline
\end{tabular}

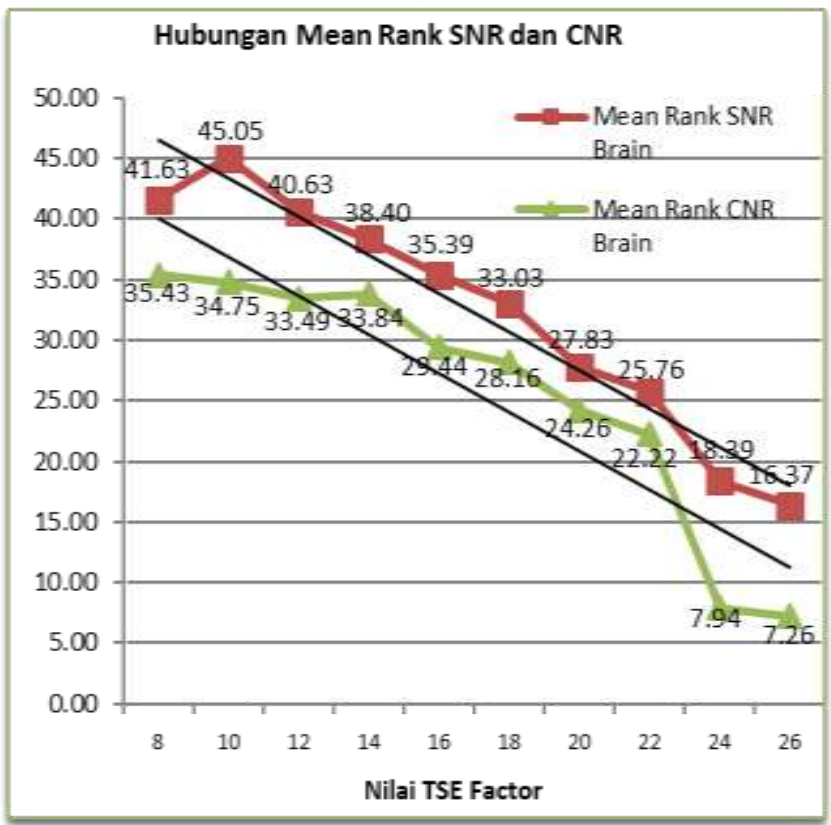

Gambar 7. Grafik hubungan mean rank SNR dan CNR brain

Nilai TSE factor yang digunakan pada pemeriksaan MRI brain di Rumah Sakit Siloam Surabaya adalah 14. Nilai TSE factor 14 berada pada urutan ke 4 mean rank SNR dan urutan 
ke 3 mean rank CNR brain. Diperoleh mean rank SNR pada TSE factor 14 adalah 38,40 dan pada CNR adalah 33,84. Berdasarkan hasil penelitian maka nilai TSE factor yang optimal digunakan pada pemeriksaan MRI brain adalah nilai TSE factor 10 untuk SNR dengan nilai mean rank 45,05 dan TSE factor 8 untuk CNR dengan nilai mean rank 35,43.

\section{DISKUSI}

\section{Pengaruh TSE factor terhadap SNR dan CNR pada} pembobotan T2 TSE potongan axial MRI brain

Berdasarkan SNR hasil uji regresi linier disertai tingkat hubungan koefisien korelasi, maka dapat disimpulkan bahwa nilai TSE factor mempengaruhi SNR, SNR adalah perbandingan besarnya amplitudo sinyal dengan amplitudo noise. Menurut Westbrook, et. al. (2014) TSE factor yang digunakan pada pemeriksaan MRI brain adalah TSE factor yang panjang. TSE factor yang panjang terkait dengan penurunan pada SNR dan CNR keseluruhan karena echo-echo selanjutnya akan lemah. TSE factor adalah jumlah pulsa $180^{\circ}$ yang akan mengisi baris dalam $k$-space pada tiap TR. Nilai TSE factor yang digunakan pada penelitian tersebut adalah 10 - 25. Menurut Anonim (2013) 10 - 25 merupakan TSE factor yang panjang. Penelitian tersebut juga menggunakan nilai TSE factor yang berada di luar rentang TSE factor panjang yaitu 8 dan 26. Kecenderungan grafik pada 3 area yaitu grey matter, white matter dan CSF memiliki kecenderungan turun. Terdapat kenaikan nilai SNR hanya pada nilai TSE factor 8 menuju nilai TSE factor 10 kemudian menurun sampai nilai TSE factor 26.

Berdasarkan hasil tersebut pada awal nilai TSE factor terdapat ketidaksesuian dengan teori. Semakin tinggi nilai TSE factor maka nilai SNR akan semakin rendah. Ketidaksesuian terdapat pada nilai SNR dengan TSE factor 10 lebih tinggi daripada nilai TSE factor 8 . Hal tersebut dapat disebabkan setting pemeriksaan MRI brain pada pesawat MRI Philips Achieva 1,5 T yang digunakan adalah menggunakan TSE factor yang panjang, sedangkan TSE factor 8 tidak termasuk pada rentang TSE factor yang panjang.

Protokol pada masing-masing pesawat didesain khusus untuk parameter instrinsik maupun ekstrinsiknya. Dapat terjadi perubahan parameter lain apabila dilakukan perubahan pada parameter yang lainnya. Pada pesawat MRI Philips Achieva 1,5 T perubahan TSE factor menyebabkan perubahan parameter lain. TR yang digunakan pada pemeriksaan MRI brain adalah shortest. Apabila dilakukan perubahan TSE factor maka Act. TR ikut mengalami perubahan. Pesawat MRI akan menyesuaikan agar diperoleh relative signal level yang $100 \%$ dan Specific Absorption Rate (SAR) yang disesuaikan dengan berat badan pasien, sehingga dapat menyesuaikan panas yang diterima tubuh. Act. TR pada nilai TSE factor 8 adalah $4083 \mathrm{~ms}$, Act. TR pada nilai TSE factor 10 adalah $4068 \mathrm{~ms}$, Act. TR pada nilai TSE factor 12 adalah $4057 \mathrm{~ms}$, Act. TR pada nilai TSE factor 14 adalah 4045 ms, Act. TR pada nilai TSE factor 16 adalah $4029 \mathrm{~ms}$, Act. TR pada nilai TSE factor 18 adalah $4014 \mathrm{~ms}$, Act. TR pada nilai TSE factor 20 adalah $4005 \mathrm{~ms}$, Act. TR pada nilai TSE factor 22 adalah 4004 ms, Act. TR pada nilai TSE factor 24 adalah 2029 ms, dan Act. TR pada nilai TSE factor 16 adalah 2025 ms. Keseluruhan Act. TR yang diperoleh adalah TR panjang yaitu $\geq 2000 \mathrm{~ms}$. Semakin tinggi TSE factor maka semakin rendah Act. TR yang diperoleh.

Faktor lain yang mempengaruhi SNR selain TSE factor yaitu faktor inherensi jaringan (obyek), faktor komponen MRI dan faktor teknis. Faktor inherensi jaringan seperti densitas proton daerah yang diperiksa, semakin tinggi densitas proton maka semakin tinggi nilai SNR yang dihasilkan, waktu relaksasi T2 yang pendek menyebabkan SNR meningkat, adanya gerakan fisiologis seperti aliran darah, CSF dan chemical shift pada obyek menyebabkan SNR menurun. Faktor komponen MRI seperti magnet utama, shim coil, radiofrekuensi coil dan sistem komputer. Jika komponen MRI tidak terawat dan terkalibrasi dengan baik akan menyebabkan kekuatan medan magnet dan tingkat homogenitasnya menurun sehingga sinyal menurun danoise meningkat. Kemudian faktor teknis, berupa parameter yang digunakan seperti TR yang panjang dapat meningkatkan SNR dan TR yang pendek dapat mengurangi SNR. Penggunaan coil yang dipasang sedekat mungkin dengan obyek akan meningkatkan SNR (Westbrook et. al, 2011).

Setelah pengukuran SNR, diteruskan dengan pengukuran CNR. Berdasarkan hasil uji regresi linier disertai tingkat hubungan koefisien korelasi, maka dapat disimpulkan bahwa nilai TSE factor mempengaruhi CNR dan memiliki grafik dengan kecenderungan turun. Semakin tinggi TSE factor maka CNR semakin rendah. Hasil penelitian tersebut sesuai dengan teori. TSE factor dapat mempengaruhi CNR, karena CNR merupakan perbedaan SNR dari area yang berdekatan.

Setiap organ memiliki nilai inherensi jaringan yang berbeda-beda. Nilai proton densitas yang terkandung pada setiap area memiliki nilai yang berbeda-beda. Grey matter merupakan badan sel saraf yang berwarna abu-abu sampai coklat. White matter disusun oleh axon yang berada di bawah cortex dan merupakan serabut yang panjang di antara neuron. Sedangkan CSF mengandung cairan. Area yang digunakan adalah area yang berdakatan. Area grey matter yang digunakan adalah pada area caudate nucleus di bagian tengah dan pada pembobotan T2 TSE tampak intermediete hiperintens, area white matter yang digunakan adalah pada area corpus callosum genu di bagian tengah dan pada pembobotan T2 TSE tampak intermediete hipointens, dan area CSF yang digunakan berada pada ventrikel lateral di bagian frontal horn dan pada T2 TSE akan tampak hiperintens. CNR yang baik akan dapat menunjukkan perbedaan daerah yang berdekatan.

SNR mempengaruhi CNR, sehingga perubahan TSE factor juga mempengaruhi CNR. Faktor lain yang mempengaruhi CNR selain TSE factor yaitu dengan menggunakan kontras media, menggunakan pembobotan sekuen T2, memilih magnetization transfer dan menghilangkan gambaran jaringan normal dengan spectral pre-saturation atau menggunakan Short Tau Inversion Recovery (STIR) dan Fluid Attenuatted Inversion Recovery (FLAIR) untuk menekan jaringan tertentu (Westbrook et. al, 2011) 
Nilai TSE factor yang paling optimal untuk menghasilkan SNR dan CNR pada pemeriksaan MRI brian pembobotan T2 TSE potongan axial

Pada penelitian tersebut, sebagian besar menunjukkan bahwa semakin tinggi TSE factor maka nilai SNR dan CNR semakin rendah, akan tetapi memberikan waktu scanning yang lebih cepat. Waktu scanning untuk nilai TSE factor $8=4$ menit 9,1 detik; waktu scanning untuk nilai TSE factor $10=3$ menit 19,3 detik; waktu scanning untuk nilai TSE factor $12=$ 2 menit 46,4 detik; waktu scanning untuk nilai TSE factor 14 = 2 menit 21,6 detik; waktu scanning untuk nilai TSE factor $16=2$ menit 4,9 detik; waktu scanning untuk nilai TSE factor 18 = 1 menit 48,4 detik; waktu scanning untuk nilai TSE factor $20=1$ menit 40,1 detik; waktu scanning untuk nilai TSE factor $22=1$ menit 32,1 detik; waktu scanning untuk nilai TSE factor $24=1$ menit 25,2 detik; dan waktu scanning untuk nilai TSE factor $26=1$ menit 16,9 detik.

SNR dan CNR adalah kriteria kualitas citra yang penting, sehingga dapat digunakan untuk menghasilkan citra yang baik dengan kontras yang baik, waktu scanning yang lebih pendek, resolusi yang lebih tinggi dan lebih sedikit artefak. Berdasarkan penelitian tersebut, nilai SNR yang paling optimal adalah pada nilai TSE factor 10. Sedangkan untuk CNR, nilai CNR yang paling optimal adalah pada nilai TSE factor 8 .

TSE factor 14 merupakan standar TSE factor di Rumah Sakit Siloam Surabaya. Digunakannya TSE factor 14 karena tidak terlalu panjang atupun tidak terlalu pendek, sehingga waktu scanning tidak terlalu lama akan tetapi juga memberikan kontribusi SNR dan CNR yang tidak terlalu rendah. Keseluruhan waktu scanning dengan sequence lengkap untuk pemeriksaan MRI brain adalah kurang lebih 45 menit, maka dari itu digunakan sequence pada pembobotan T2 TSE yang tidak terlalu lama dengan menggunakan TSE factor 14 yang memilik waktu scanning 2 menit 21,6 detik.

Secara teori tidak terdapat tinjauan khusus tentang standar nilai TSE factor pada pemeriksaan MRI brain, hanya saja pada Westbrook(2014) menunjukkan pada MRI brain 1,5 T digunakan TSE factor $\geq 16$ akan tetapi tidak spesifik pada merk pesawat MRI. Setiap pesawat mempunyai standar atau komposisi pesawat yang berbeda dengan pesawat lain.

Penggunaan nilai TSE factor yang tepat sangat diperlukan dalam menghasilkan kualitas citra yang baik, terutama SNR dan CNR. Dengan kualitas citra yang baik maka dapat memberikan informasi anatomi dan diagnostik yang lebih baik.

\section{SIMPULAN}

Ada pengaruh nilai TSE factor terhadap SNR dan CNR pada pembobotan T2 TSE potongan axial MRI brain. Secara keseluruhan hasil pengukuran SNR dan CNR setiap area memiliki nilai significant hasil uji regresi linier $\left(0,000^{*}\right)<p$ value $(0,05)$. Pada SNR, ada korelasi yang sedang dan kuat antara nilai TSE factor terhadap SNR grey matter, nilai TSE factor terhadap SNR white matter dan nilai TSE factor terhadap SNR CSF. Pada CNR, ada korelasi yang kuat antara nilai TSE factor terhadap CNR CSF - grey matter dan nilai TSE factor terhadap CNR CSF - white matter.

Nilai TSE factor yang menghasilkan SNR dengan optimal pada pembobotan T2 TSE MRI potongan axial MRI brain dengan optimal adalah nilai TSE factor 10 dengan niali mean rank 45,05. Sedangkan nilai TSE factor yang menghasilkan CNR dengan optimal pada pembobotan T2 TSE potongan axial MRI brain dengan optimal adalah nilai TSE factor 8 dengan nilai mean rank 35,43

Penggunaan parameter TSE factor sebaiknya tidak terlalu panjang ( > 20), karena dengan memperbanyak nilai TSE factor maka akan menyebabkan citra mengalami blurring (pengkaburan), yang akan mengakibatkan penurunan nilai SNR dan CNR.

\section{DAFTAR PUSTAKA}

Anonim. 2013. MR System Achieva. Philips Helthcare : US

Elster, AD. 2015. FSE Paramaters. http://mriquestions.com/fseparameters.html, diakses pada tanggal 1 Maret 2017.

Cooper, C. 2012. Brain MRI: A Systematic Reading. https://neurosurgery basics.com/brain/brain-mri-a-systematic-reading/, diakses pada tanggal 12 Maret 2017.

Muzio, DB, et al. 2017. Brain Tumour Protocol (MRI) https://radiopaedia.org/ articles/brain-tumour-protocol-mri, diakses pada tanggal 16 Maret 2017.

Simanjuntak, J, dkk. 2014. Studi Analisis Echo Train Length dalam K-Space serta Pengaruhnya terhadap Kulaitas Citra Pembobotan T2 FSE pada MRI 1,5 T. Jurusan Fisika Undip Semarang : Semarang.

Westbrook, C, et al. 2011. MRI In Practice Fourth Edition. Wiley Blackwell $\mathrm{UK}$.

Westbrook, C. 2014. Handbook of MRI Technique Fourth Edition. Wiley Blackwell UK. 